\title{
HUBUNGAN DUKUNGAN SUAMI TERADAP KEJADIAN POSTPARTUM BLUES DI WILAYAH KERJA PUSKESMAS PAYUNG SEKAKI KOTA PEKANBARU TAHUN 2017
}

\author{
Alifia Khana Fitrah ${ }^{1}$, Siska Helina ${ }^{2}$, Hamidah ${ }^{2}$ \\ *Jurusan Kebidanan Poltekkes Kemenkes Riau
}

\begin{abstract}
ABSTRAK
Postpartum blues dikategorikan sebagai gangguan mental ringan sehingga sering tidak dipedulikan, tidak terdiagnosa dan akhirnya tidak ditangani, keadaan ini akan membuat perasaan tidak nyaman bagi wanita yang mengalaminya, sehingga mempunyai dampak lebih buruk terutama dalam masalah hubungan dengan suami dan perkembangan anak. Tujuan dari penelitian ini adalah untuk mengetahui angka kejadian postpartum blues, untuk mengetahui distribusi frekuensi dukungan suami, dan untuk mengetahui hubungan dukungan suami terhadap kejadian postpartum blues. Penelitian ini dilakukan pada bulan September 2016 hingga Juni 2017 di wilayah kerja Puskesmas Payung Sekaki Kota Pekanbaru. Metode penelitian adalah deskriptif analitik dengan desain cross sectional. Populasi dalam penelitian ini adalah seluruh ibu postpartum multipara yang berada di Klinik Pratama wilayah kerja Puskesmas Payung Sekaki Kota Pekanbaru. Teknik sampling yang digunakan adalah consecutive sampling berjumlah 45 orang ibu postpartum dilakukan dengan cara home visit. Analisis data dilakukan secara univariat dan bivariat menggunakan uji Chi-square dengan tingkat kemaknaan 95\% $(\alpha \leq 0,05)$. Hasil penelitian ditemukan angka kejadian postpartum blues $26,7 \%$, distribusi frekuensi dukungan suami $57,8 \%$, dan ada hubungan dukungan suami terhadap kejadian postpartum blues di wilayah kerja Puskesmas Payung Sekaki Kota Pekanbaru tahun 2017. Saran dalam penelitian ini diharapkan kepada bidan yang berpraktik di wilayah kerja Puskesmas Payung Sekaki untuk mengadakan kelas ibu nifas dengan menghadirkan suami sebagai pendamping ibu.
\end{abstract}

\section{Kata Kunci : Dukungan Suami, Postpartum Blues \\ Daftar Puskata : $33(2002-2014)$}

\section{PENDAHULUAN}

Postpartum merupakan masa enam minggu sejak bayi lahir sampai organorgan reproduksi wanita kembali kebentuk normal seperti sebelum hamil. Masa ini akan menyebabkan perubahanperubahan pada organ reproduksi serta kondisi kejiwaan (psikologis) yang mengakibatkan ibu membutuhkan penyesuaian diri pada minggu-minggu pertama setelah melahirkan. Sebagian ibu berhasil menyesuaikan diri dengan baik, tetapi ada sebagian lainnya yang tidak berhasil dalam menyesuaikan dirinya dan mengalami gangguan psikologis yang lebih dikenal dengan istilah postpartum
blues.Postpartum blues merupakan sindrom gangguan mental ringan yang dialami oleh ibu nifas yang berlangsung pada minggu pertama postpartum sehingga sering tidak dipedulikan oleh suami, keluarga dan tenaga kesehatan sebagaimana mestinya. Apabila hal ini tidak ditangani dengan baik maka gangguan ini dapat berkembang menjadi depresi postpartum hingga psikosis postpartum. (Mansur, H, 2009)

Angka kejadian postpartum blues di beberapa negara seperti Jepang berkisar 15-50\%, Amerika Serikat 27\%, Prancis 31,3\%, Yunani 44,5\%. Prevalensi untuk Asia berkisar 26-85\%. Sedangkan 
angka kejadian postpartum blues di Indonesia cukup tinggi berkisar 50-70\%. Namun untuk Kota Pekanbaru tidak ditemukan angka pasti mengenai kejadian postpartum blues. Hal ini menjadi tanggung jawab tenaga kesehatan untuk menerapkan skrining EPDS (Edinburgh Postnatal Depression Scale) sehingga didapatkan gambaran kejadian postpartum blues di Kota Pekanbaru. (Ratna, 2009)

Berdasarkan penelitian sebelumnya yang dilakukan oleh Setyowati dan Uke, $\mathrm{R}$ (2006) penyebab terjadinya postpartum blues adalah pengalaman yang tidak menyenangkan pada periode kehamilan dan persalinan $(38,71 \%)$, faktor psikososial (19,35\%), kualitas dan kondisi bayi baru lahir $(16,13 \%)$, serta faktor spiritual $(9,78 \%)$.

Penelitian yang dilakukan oleh Fatimah, S (2009) di Kota Semarang menunjukkan $44 \%$ ibu yang tidak mendapatkan dukungan suami mengalami postpartum blues dan 56\% ibu yang mendapatkan dukungan suami tidak mengalami postpartum blues. Hasil penelitian yang dilakukan oleh Misrawati, L. W dan Utami tahun 2014 di RSUD Arifin Ahmad Pekanbaru angka kejadian postpartum blues sekitar 16,7\%. Namun untuk angka kejadian postpartum blues di Kota Pekanbaru hingga saat belum dapat diketahui secara pasti dikarenakan belum adanya lembaga terkait yang melakukan penelitian terhadap kasus ini serta sistem pencatatan dan pelaporan yang belum lengkap.

Pengalaman praktik peneliti diwilayah kerja Puskesmas Rumbai kelurahan Limbungan dari 4 orang ibu postpartum terdapat 1 orang ibu postpartum yang mengalami postpartum blues. Sedangkan pengalaman praktik peneliti di wilayah kerja Puskesmas Rawat Inap Sidomulyo didapatkan 2 orang ibu postpartum yang mengalami postpartum blues. Hal ini disebabkan oleh kurangnya dukungan suami dalam merawat bayi. Suami melimpahkan semua tanggung jawab kepada istri dalam merawat bayi dan tidak peduli terhadap masalah yang ibu alami.

Data dari Dinas Kasehatan Kota Pekanbaru jumlah persalinan terbanyak di kota Pekanbaru berada di wilayah kerja Puskesmas Payung Sekaki Kota Pekanbaru. Survei awal yang dilakukan oleh peneliti di Klinik Pratama Afiyah dan Klinik Pratama Bakti wilayah kerja Puskesmas Payung Sekaki didapatkan bahwa ada beberapa ibu postpartum yang mengalami tanda dan gejala postpartum blues pada minggu pertama setelah melahirkan seperti kurangnya perhatian ibu dalam merawat anak, tidak mau menyusui anaknya dan tidak dapat mengontrol emosi. Namun, karena gejala tersebut tidak berlanjut pada mingguminggu selanjutnya dan ibu tidak ada keluhan sehingga bidan tidak menindaklanjuti masalah ini.

Dukungan suami merupakan faktor terbesar dalam memicu kejadian postpartum blues. Hal ini dikarenakan dukungan suami merupakan strategi koping penting pada saat mengalami stress dan berfungsi sebagai strategi preventif untuk mengurangi stress. Mereka yang mendapatkan dukungan suami baik secara emosional, support, penghargaan relatif tidak menunjukkan gejala postpartum blues, sedangkan mereka yang kurang memperoleh dukungan suami relatif mengalami gejala postpartum blues. Dukungan dari tenaga kesehatan seperti dokter obstetri bidan atau perawat juga sangat di perlukan oleh ibu postpartum misal dengan cara memberikan informasi yang memadai/ adekuat tentang proses kehamilan dan persalinan termasuk penyulit-penyulit yang mungkin akan timbul pada masa tersebut beserta penangannya. (Sanjaya, $\mathrm{dkk}, 2013$ ).

Berdasarkan latar belakang tersebut peneliti tertarik untuk melakukan penelitian yang berjudul " Hubungan Dukungan Suami Terhadap Kejadian Postpartum Blues di Wilayah Kerja 
Puskesmas Payung Sekaki Kota Pekanbaru Tahun 2017"

\section{METODE PENELITIAN}

Jenis penelitian bersifat kuantitatif analitik dengan pendekatan cross sectional. Penelitian dilaksanakan pada bulan September 2016 hingga Juni 2017 di Klinik Pratama Afiyah, Klinik Pratam Bakti, dan Klinik Pratama Jambu Mawar Kota Pekanbaru. Populasi adalah ibu postpartum dan sampel berjumlah 45 orang. Pengolahan data dilakukan secara komputerisasi dengan analisa data bivariat menggunakan uji statistik Chisquare.

\section{HASIL PENELITIAN}

\section{Analisis Univariat}

Tabel 1. Distribusi Frekuensi Dukungan Suami Di Wilayah Kerja Puskesmas Payung Sekaki Kota Pekanbaru Tahun 2017

\begin{tabular}{cccc}
\hline No & Dukungan Suami & F & $\%$ \\
\hline 1 & Baik & 26 & 57,8 \\
2 & Kurang & 19 & 42,2 \\
\hline & Jumlah & 45 & 100 \\
\hline
\end{tabular}

\section{Analisis Bivariat}

Tabel 2. Distribusi Frekuensi Dukungan Suami Di Wilayah Kerja Puskesmas Payung Sekaki Kota Pekanbaru Tahun 2017

\begin{tabular}{cccc}
\hline No & Postpartum Blues & $F$ & $\%$ \\
\hline 1 & Ya & 12 & 26,7 \\
2 & Tidak & 33 & 73,3 \\
\hline & Jumlah & 45 & 100 \\
\hline
\end{tabular}

\section{Analisa Bivariat}

Tabel 3. Hubungan Dukungan Suami Dengan Postpartum Blues Di Wilayah Kerja Puskesmas Payung Sekaki Kota Pekanbaru Tahun 2017

\begin{tabular}{|c|c|c|c|c|c|c|c|}
\hline \multirow{3}{*}{ No } & \multirow{3}{*}{$\begin{array}{c}\text { Dukungan } \\
\text { Suami }\end{array}$} & \multicolumn{4}{|c|}{ Postpartum Blues } & \multirow{3}{*}{$\mathrm{f}$} & \multirow{3}{*}{$\begin{array}{c}P \\
\text { Value }\end{array}$} \\
\hline & & \multicolumn{2}{|c|}{$\mathrm{Ya}$} & \multicolumn{2}{|c|}{ Tidak } & & \\
\hline & & $f$ & $\%$ & $\mathrm{f}$ & $\%$ & & \\
\hline 1 & Baik & 1 & 3,8 & 25 & 96,2 & 26 & \multirow{2}{*}{0,000} \\
\hline \multirow[t]{2}{*}{2} & Kurang & 11 & 57,9 & 8 & 42,1 & 19 & \\
\hline & Total & 12 & 26,7 & 33 & 73,3 & 45 & \\
\hline
\end{tabular}

\section{PEMBAHASAN}

1. Dukungan Suami

Berdasarkan penelitian yang telah dilakukan pada ibu postpartum di Wilayah Kerja Puskesmas Payung Sekaki Kota Pekanbaru Tahun 2017 didapatkan hasil bahwa ibu postpartum yang memiliki dukungan suami kurang adalah sebanyak 19 orang $(42,2 \%)$ dan yang mendapatkan dukungan suami baik adalah sebanyak 26 orang $(57,8 \%)$. Hasil tersebut dapat disimpulkan bahwa ratarata ibu postpartum kurang mendapatkan dukungan suami.

Ibu postpartum sangat membutuhkan dukungan dan perhatian dari suami untuk membantu ibu dalam mendapatkan kepercayaan diri dan harga diri sebagai seorang istri. Dukungan suami yang diberikan pada ibu postpartum dalam bentuk kerjasama yang baik, serta memberikan dukungan moral dan emosional. Dengan perhatian suami membuat istri merasa lebih yakin, bahwa ia tidak saja tepat menjadi istri, tetapi istri juga akan bahagia menjadi (calon) ibu bagi anak yang dikandungnya. (Adhim, M. F 2002)

Hasil penelitian yang dilakukan oleh Yuliawan, D, (2014) mengenai dukungan suami terhadap kesejahteraan ibu nifas didapatkan hasil bahwa nilai rata-rata 296,61 dengan nilai terendah 156 dan nilai tertinggi 402 dan standar deviasi 50,257. Persentase dukungan suami pada penelitian yang dilakukan 
oleh Fatimah, S (2014) yaitu responden yang mendapatkan dukungan suami kurang sebanyak 4 orang (16\%), sedangkan responden yang mendapatkan dukungan suami sedang sebanyak 15 orang $(60 \%)$, dan responden yang mendapatkan dukungan suami tinggi sebanyak 6 orang $(24 \%)$.

Pada kuesioner penelitian terdapat 5 bentuk dukungan suami yang dinilai. Namun, dari 5 bentuk dukungan tersebut yang banyak tidak diberikan pada ibu postpartum adalah dukungan informasional, dukungan penghargaan dan dukungan kelompok. Dukungan informasional sangat berperan penting dalam membantu ibu dan suami dalam merawat bayinya. dukungan informasional yang dapat diberikan oleh suami seperti menanyakan ibu hal yang tidak dimengerti dalam merawat bayi, menyediakan fasilitas informasi (televisi, majalah, internet) serta suami mendampingi ibu saat tenaga kesehatan memberikan informasi mengenai cara merawat bayi. Bentuk dukungan tersebut jika diberikan secara maksimal oleh suami maka akan membuat ibu tidak merasa berperan sendiri dalam merawat bayinya.

Dukungan suami yang tidak diberikan selanjutnya adalah dalam bentuk penghargaan. Adapaun bentuk dukungan penghargaan yang dapat diberikan oleh suami adalah mengingatkan ibu untuk memenuhi kebutuhan nutrisi ibu dan bayi, suami selalu menanyakan kondisi ibu, suami tidak melarang ibu mengkonsumsi makanan yang baik untuk gizi ibu, serta suai selalu menanyakan masalah yang ibu rasakan selama masa nifas. Dukungan penghargaan sangat berperan dalam memberikan rasa perhatian kepada ibu selama masa nifasnya.

Dukungan suami terakhir yang tidak diberikan adalah dukungan kelompok. Adapun bentuk dukungan kelompok yang dapat diberikan oleh suami adalah suami melibatkan ibu dalam menentukan nama bayi mereka, suami selalu menanyakan perkembangan bayi mereka, suami selalu mengajak ibu membeli perlengkapan bayi, serta suami selalu peduli apabila bayi mereka menangis dimalam hari. Dukungan sangat berperan dalam menciptakan kerjasama antara ibu dan suami dalam merawat bayi mereka.

Dari hasil penelitian sebagian besar responden tidak mendapatkan dukungan tersebut secara maksimal. Sebagaimana diketahui bahwa dukungan penuh dari suami adalah hal yang terpenting bagi ibu postpartum. Dukungan suami tidak dapat diremehkan dan sangat penting dalam membangun suasana positif. Oleh karena itu, dukungan atau sikap positif dari suami akan memberikan kekuatan tersendiri bagi ibu selama menjalani masa nifasnya.

\section{Kejadian Postpartum Blues}

Berdasarkan hasil penelitian diketahui bahwa proporsi ibu postpartum yang mengalami postpartum blues adalah sebanyak 12 orang $(26,7 \%)$ dibandingkan dengan ibu postpartum yang tidak mengalami postpartum blues adalah sebanyak 33 orang $(73,3 \%)$. Berdasarkan hasil kuesioner yang diperoleh dari $12 \mathrm{ibu}$ yang mengalami postpartum blues kebanyakan memiliki gejala seperti menyalahkan diri sendiri, merasa cemas atau khawatir tanpa alasan yang jelas, merasa takut atau panik tanpa alasan yang jelas, merasa segala sesuatunya sulit untuk dikerjakan, serta merasa tidak bahagia hingga mengalami kesulitan untuk tidur.

Ibu postpartum dikatakan postpartum blues ketika ibu postpartum mengalami perubahan mood yang terjadi setiap waktu setelah ibu melahirkan, tetapi sering terjadi pada hari ke-3 dan ke-4 postpartum dan memuncak antara hari ke-5 dan ke-14 pospartum yang ditandai dengan tangisan singkat, perasaan kesepian atau ditolak, cemas, 
bingung, gelisah, letih, pelupa, dan tidak dapat tidur. (Bobak, 2005)

Berdasarkan teori yang

dikemukakan oleh Henshaw (2003) menjelaskan tentang tanda gejala postpartum blues terdiri dari; perasaan sedih, tidak dapat mengontrol emosi, mengalami perubahan perasaan, bingung, cemas dan gangguan kognitif (kurang perhatian, tidak bisa konsentrasi, dan pelupa).

Penyebab dari postpartum blues belum diketehui secara pasti, tapi diduga disebabkan oleh berbagai faktor, antara lain perubahan biologis, stress dan penyebab sosial atau lingkungan. Perubahan kadar hormon estrogen, progesteron, konrtikotropin dan endorphin serta prolaktin diduga menjadi faktor pendukung terjadinya postpartum blues. Faktor sosial dan lingkungan yang dapat menjadi faktor pendukung terjadinya postpartum blues antara lain tekanan dalam hubungan pernikahan dan hubungan keluarga, riwayat syndrome pramenstruasi, rasa cemas dan takut terhadap persalinan dan penyesuaian yang buruk terhadap peran maternal (Regina, 2011).

Dari hasil penelitian ditemukan sebanyak 12 orang ibu nifas mengalami postpartum blues. Data tersebut menunjukkan angka kejadian postpartum blues di wilayah kerja Puskesmas Payung Sekaki Kota Pekanbaru. Hal ini tentu menjadi perhatian bagi tenaga kesehatan untuk menangani kasus postpartum blues dan mencegah agar tidak ditemukan lagi angka kejadian postpartum blues.

Gambaran penelitian ini sejalan dengan penelitian yang dilakukan oleh Fatimah, S (2014) yang dilakukan di ruang bugenvile RSUD Tugurejo semarang dari 25 responden menunjukkan bahwa 11 orang (44\%) terjadi gejala postpartum blues sedangkan 14 orang tidak ada gejala postpartum blues. Ibu yang mengalami hal tersebut membutuhkan dukungan psikologis maupun fisik. Mereka membutuhkan kesempatan untuk mengekspresikan pikiran dan perasaan dari situasi yang menakutkan.

Berdasarkan hasil penelitian penulis dan penelitian yang dilakukan oleh Fatimah, S (2014) dapat diketahui bahwa disetiap daerah memiliki angka kejadian postpartum blues yang bervariasi. Hal ini dapat disebabkan karena berbagai faktor seperti dukungan keluarga ataupun lingkungan. Hal ini didukung oleh teori yang dikemukakan oleh Bobak (2005) bahwa kejadian postpartum blues dapat dipengaruhi oleh faktor perubahan biologis, terjadinya fluktuasi hormon, situasi stres, respon psikologis, serta permasalahan sosial dalam lingkungan.

\section{Hubungan Dukungan Suami Dengan Kejadian Postpartum Blues}

Berdasarkan hasil penelitian yang telah dilakukan didapatkan hasil bahwa ibu postpartum yang kurang mendapatkan dukungan suami mengalami postpartum blues adalah sebanyak 11 orang $(57,9 \%)$ dibandingkan dengan ibu postpartum yang mendapatkan dukungan suami baik mengalami postpartum blues sebanyak 1 orang (3,8\%). Hasil uji statistik didapatkan nilai $p=0,000$, berarti dapat disimpulkan adanya hubungan yang signifikan antara dukungan suami dengan kejadian postpartum blues.

Hal ini mendukung pendapat yang dikemukakan oleh Videbeck (2008) yaitu dukungan suami merupakan faktor terbesar untuk memicu terjadinya postpartum blues. Hal ini dikarenakan dukungan suami merupakan strategi koping penting pada saat mengalami stress dan berfungsi sebagai strategi preventif untuk mengurangi stress.

Penelitian ini juga sejalan dengan penelitian yang dilakukan oleh Yulianti (2013) mengenai hubungan dukungan keluarga dengan postpartum blues di wilayah kerja puskesmas kajhu 
kecamatan baitussalam kabupaten aceh besar tahun 2013 bahwa dari 85 responden yang mendapatkan dukungan keluarga mengalami postpartum blues sebanyak 34 responden $(40 \%)$ dan yang tidak mengalami postpartum blues sebanyak 51 responden $(60 \%)$ dan dari 67 responden $(100 \%)$ yang tidak mendapat dukungan keluarga, mengalami postpartum blues sebanyak 41 responden $(61,21 \%)$ dan yang tidak mengalami postpartum blues sebanyak 26 responden $(38,8 \%)$

Seorang suami merupakan salah satu anggota keluarga yang sangat dekat dengan ibu. Segala bentuk tindakan yang dilakukan suami yang berkaitan dengan masa nifas ibu akan berdapak pada keadaan psikologis ibu serta kelancaran ibu dalam menjalani masa nifasnya. Dukungan yang positif dari suami sangat diperlukan dalam membantu kondisi ibu selama masa nifas. Apabila suami tidak mendukung ibu postpartum maka dapat membuat ibu merasa sedih dan kewalahan dalam mengasuh bayinya pada minggu pertama postpartum. Dukungan suami merupakan bentuk interaksi yang didalamnya terdapat hubungan yang saling memberi dan menerima bantuan yang bersifat nyata. Sehingga dapat memberikan rasa cinta dan perhatian.

Berdasarkan hasil penelitian ditemukan bahwa dari 12 ibu postpartum yang mengalami postpartum blues terdapat 1 orang yang memiliki dukungan suami yang baik. Menurut asumsi peneliti, hal ini terjadi dikarenakan seseorang yang mengalami postpartum blues tidak hanya dipengaruhi oleh 1 fator saja seperti dukungan suami. Faktor pemungkin lainnya yang dapat menyebabkan terjadinya postpartum blues seperti paritas, kondisi ekonomi keluarga, serta tingkat pengetahuan ibu postpartum. hal ini dapat dilihat dari data milik responden bahwa responden memiliki 3 orang anak dengan jarak anak yang dekat, pendapatan keluarga <UMR serta tingkat pengetahuan ibu yang kurang. Hal ini didukung dengan teori yang dikemukakan oleh Yanti, D, dkk (2009) menyatakan bahwa faktor penyebab terjadinya postpartum blues adalah faktor hormonal, umur dan paritas, pengalaman dalam proses kehamilan dan persalinan, serta latar belakang psikologi wanita yang bersangkutan seperti tingkat pendidikan, status perkawinan, kehamilan yang tidak diinginkan, riwayat gangguan kejiwaan, status sosial ekonomi, serta keadekuatan dukungan sosial dari lingkungannya.

Berdasarkan hasil penelitian ini dapat dilihat bahwa terdapat hubungan dukungan suami terhadap kejadian postpartum blues. Selain itu hasil analisa bivariat menunjukkan bahwa nilai $p$ 0,000 kecil dari 0,05 yang artinya ada hubungan yang signifikan. Dukungan suami sangat dibutuhkan dalam memberikan pengaruh yang positif terhadap ibu postpartum selama menjalani masa nifasnya. Kerja sama yang baik antara ibu dan suami akan menciptakan kondisi yang kondusif bagi ibu postpartum dalam merawat diri dan bayinya.

\section{KESIMPULAN}

a. Responden yang mengalami postpartum blues adalah sebanyak $26,7 \%$.

b. Responden yang kurang mendapatkan dukungan suami adalah sebanyak $42,2 \%$.

c. Ada hubungan antara dukungan suami dengan kejadian postpartum blues dengan $p$ value $0,000<\alpha 0,05$.

\section{SARAN}

a. Bagi Bidan Pada Tempat Penelitian

Diharapkan kepada tenaga kesehatan khususnya bidan di Wilayah Kerja Puskesmas Payung Sekaki Kota Pekanbaru agar membuat kelas ibu nifas dengan menghadirkan suami sebagai pendamping ibu.

b. Bagi Institusi Pendidikan 
Diharapkan kepada institusi pendidikan agar dapat melengkapi buku-buku sumber mengenai dukungan suami dan postpartum blues.

c. Bagi Peneliti Lain

Merupakan bahan masukan dan informasi awal yang dapat digunakan untuk penelitian selanjutnya dan juga dapat menambahkan faktor-faktor lain yang berpengaruh.

\section{DAFTAR PUSTAKA}

Adhim, M. F. 2002. Indahnya Pernikahan Dini. Jakarta: Gema Insani.

Bobak. 2005. Buku Ajar Keperawatan Maternitas edisi 4. Jakarta: EGC

Cunningham, F. G. 2006. Obstetri Williams. Jakarta: EGC.

Cox, J. L, dkk. 2003. Detection of Postnatal Depresion: Development of The 10-item Edinburgh Posntal Depresion Scale. British Journal of Psychiatry, 150, 782-786. Diperoleh pada tanggal 1 April 2015 jam 21.45 dari http://www.bjp.rcpsych.org/

Dinas Kesehatan Kota Pekanbaru. 2016. Provil Kesehatan Ibu Dan Anak Kota Pekanbaru. Riau

Elvira, S. D. 2006. Depresi Pasca Persalinan. Jakarta: Fakultas Kedokteran Universitas Indonesia.

Fatimah, S. 2009. Hubungan Dukungan Suami Dengan Kejadian Postpartum Blues Pada Ibu Primipara di Ruang Bugenvile RSUD Tugurejo Semarang. Artikel Universitan Diponegoro Semarang. Diperoleh pada tanggal 03 Februari 2015 dari http://undip.ac.id/107291.pdf.

Gondo, H. K. 2012. Skrining Edinburgh Posnatal Depression Scale (EPDS) pada postpartum blues. Bagian Obstetri dan Ginekologi Fakultas Kedokteran Universitas Wijaya Kusuma Surabaya. Diperoleh tanggal 21 Maret 2015 dari http://www.elib.fk.uwk.ac.id/asset/ achieve/jurnal.pdf.

Henshaw. 2003. Postnatal Blues: A Risk Factor of Postnatal Depresion. $j$ Pychosom Obstet Gynecol, 25, 267272.

Hidayat, A. A. A. 2007. Metode penelitian Keperawatan dan Teknik Analisa Data. Jakarta: Salemba Medika.

Jacinta, R. F. 2005. Stress Kerja. Team epsikologi.com. retrivied from http://www.baliusada.com/content/ view/333/2/, diakses 2 september 2013.

Kuntjoro, Z. 2002. Dukungan Sosial Pada Lansia.http://www.epsikologi.co.id tanggal akses 15 desember 2010.

Mansur, H. 2009. Psikologi Ibu dan Anak Untuk Kebidanann. Jakarta: Salemba Medika.

Misrawati, L. W dan Utami S. 2014. Postpartum blues di Pekanbaru Public Hospital. Universitas Riau.

Nurhayati, dkk. 2012. Konsep Kebidanan. Jakarta: Salemba.

Prawirohardjo, S. 2010. Ilmu Kebidanan. Jakarta : P.T. bina Pustaka Sarwono Prawirohadjo.

Pusdiknakes. 2003. Buku 4: Asuhan Kebidanan Postpartum.

Ramyulis. 2003. Pendidikan Islam dalam Rumah Tangga. Jakarta: Kalam Mulia.

Ratna. 2009. Perawatan Pasca Melahirkan. Diambil tanggal 28 Mei 2014 dari http://ratnarespati.com/2009/0303/p erawatan-pasca-melahirkan/

Regina. 2011. Keperawatan Maternitas. Bogor: Ghalia Indonesia.

Saleha, S. 2009. Asuhan Kebidanan pada Masa Nifas. Jakarta: Salemba Medika.

Sanjaya, dkk. 2013. Penelitian Pendidikan, Jenis, Metode dan Prosedur. Jakarta: Kencana Prenada Media Group. 
Sari, E, dkk. 2014. Asuhan Kebidanan Masa Nifas. Jakarta : CV. Trans Info Media.

Sarafino, et all. 2011. Healt Psychology Biopsychosocial Interactions Seventh Edition. United States of American.

Setyowati dan Uke R. 2006. Study Faktor Kejadian Postpartum Blues Pada Ibu Pasca Salin : Penelitian deskriptif Ruang Bersalin I RSU Dr. Soetomo Surabaya. Retrived from

http://www.adln.lib.unair.ac.id/go.p hp?id= gdlhubgdls12006setyowatiu238\&w $\mathrm{idth}=300 \&$ PHPSESSID $=\mathrm{dd} 2 \mathrm{cc} 1 \mathrm{da} 3$ 10370d55fcbeb92daa70d7.

Diperoleh tanggal 23 Februaru 2010.

Soep. 2009. Pengaruh intervensi Psikoedukasi Dalam Mengatasi Depresi Postpartum di RSU Dr. Pirngadi Medan. Tesis Keperawatan Universitas Sumatra Utara.

Suhita. 2005. Diakses tanggal 15 Juli 2013

(http://www.masbow.com/2009/08/ apa.itu.dukungan-sosial.html)

Varney, H. 2007. Buku Ajar Asuhan Kebidanan. Jakarta.

Videbeck, L. 2008. Buku Ajar Keperawatan Jiwa. Jakarta: EGC

Wong, D. L, dkk. 2009. Buku Ajar Keperawatan Pediatrik, Volume 2. Jakarta: EGC.

Yanti, D, dkk. 2011. Asuhan Kebidanan Masa Nifas Belajar Menjadi Bidan Profesional. Bandung : Refika Aditama.

Yulianti. 2013. Hubungan Dukungan Keluarga Dengan Kejadian Postpartum Blues. STIKES U'Budiyah Banda Aceh

Yuliawan, D. 2014. Pengaruh Dukungan Suami Terhadap Kesejahteraan Ibu Nifas. Universitas Muhammadiyah Surakarta 